$13 ; 15$

\title{
Согласованная нагрузка на брэгговских структурах терагерцевого диапазона частот
}

\author{
(C) Д.А. Усанов ${ }^{1}$, А.В. Скрипаль ${ }^{1}$, Д.В. Пономарев ${ }^{1}$, \\ М.К. Мерданов ${ }^{2}$ \\ ${ }^{1}$ Саратовский национальный исследовательский государственный \\ университет им. Н.Г. Чернышевского, Саратов, Россия \\ ${ }^{2}$ Научно-производственный центр „Электронное приборостроение“, \\ Москва, Россия \\ E-mail: usanovda@info.sgu.ru
}

Поступило в Редакцию 20 июля 2017 г.

Создана малогабаритная широкополосная волноводная согласованная нагрузка на основе брэгговских структур, содержащая последовательно расположенные нанометровые металлические и диэлектрические слои, предназначенные для использования в диапазоне частот 140-210 $\mathrm{GHz}$. В этом диапазоне частот экспериментально получены значения коэффициента стоячей волны по напряжению менее 1.3 .

DOI: $10.21883 /$ PJTF.2018.05.45709.16979

Успешное развитие СВЧ-электроники во многом зависит от наличия соответствующей элементной базы. Одним из таких элементов, обеспечивающих функционирование СВЧ-устройств [1,2], является согласованная (неотражающая) нагрузка. Наилучшую перспективу практического применения имеют нагрузки, которые обладают совокупностью таких свойств, как широкополосность, низкий уровень отражаемой и высокий уровень рассеиваемой мощности, малые габариты. В качестве поглощающих элементов в существующих нагрузках обычно используются ферроэпоксидные композиты, обладающие большими потерями, или диэлектрические стержни с нанесенными на них слоями резистивного материала. Такие нагрузки не всегда удовлетворяют потребностям практики по габаритам, частотным характеристикам, стойкости к ударным воздействиям. Для обеспечения широкополосного согласования длина волноводных нагрузок должна в несколько раз превышать длину 
волны электромагнитного излучения во всем частотном диапазоне, в котором они используются. Геометрические размеры и электрофизические характеристики поглощающих элементов должны контролироваться с высокой точностью, что обусловливает повышенные требования к технологии их изготовления.

В сантиметровом диапазоне длин волн одним из недостатков существующих согласованных нагрузок являются их большие габариты, которые превышают в трехсантиметровом диапазоне длин волн $100 \mathrm{~mm}$. При создании нагрузок в миллиметровом диапазоне длин волн и тем более в терагерцевом диапазоне возникают дополнительные трудности. Это связано с тем, что в указанных диапазонах наблюдается частотная зависимость диэлектрической и магнитной проницаемостей ферроэпоксидных композитов и резистивных материалов, используемых в качестве поглощающих элементов.

Ряд новых возможностей при создании СВЧ согласованных нагрузок сантиметрового и миллиметрового диапазонов открывается при использовании свойств так называемых брэгговских структур с фотонной запрещенной зоной (СВЧ фотонных кристаллов) [3,4]. Отметим, что наряду с зоной, запрещенной для распространения волн в определенном диапазоне частот, как правило, вследствие почти полного отражения электромагнитной волны, для таких структур характерно наличие и разрешенной зоны. В частотном диапазоне разрешенной зоны волна не испытывает отражения и распространяется с малыми потерями. Однако в случае присутствия в таких структурах проводящих слоев (например, в виде нанометровых металлических пленок) при распространении волны в так называемой разрешенной зоне происходит ее поглощение. Такое свойство фотонных кристаллов авторами [5-9] было использовано для создания малогабаритных (с продольными размерами, не превышающими одной длины волны) согласованных нагрузок, работающих в диапазонах частот $8.15-12.05,12.05-17.44,17.44-25.95 \mathrm{GHz}$ с коэффициентом стоячей волны по напряжению $V S W R<1.10$ и в диапазонах частот $25.95-37.50,37.50-53.57 \mathrm{GHz}$ с $V S W R<1.15$.

В литературе отсутствуют сведения об использовании указанной выше возможности создания такого типа нагрузок для терагерцевого диапазона частот, работа в котором открывает новые перспективы практически значимых приложений [10-13].

Поэтому актуальной остается задача расширения диапазона рабочих частот малогабаритных согласованных нагрузок, включая терагерцевый, на основе фотонных кристаллов.

Письма в ЖТФ, 2018, том 44, вып. 5 


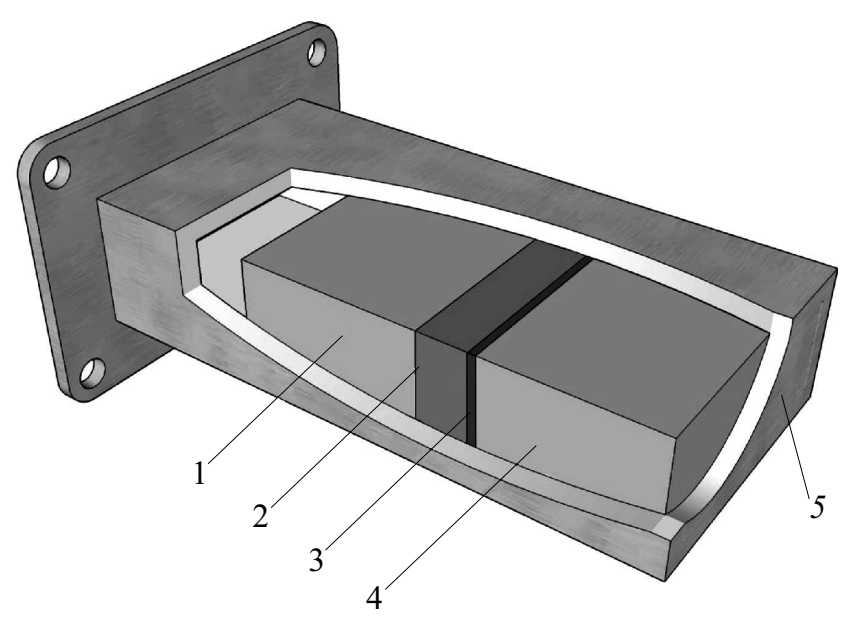

Рис. 1. Конструкция согласованной нагрузки, включающей сплошные диэлектрические слои $(\varepsilon: 1-2.0,2-9.6,4-2.0)$ и нанометровую металлическую пленку (3). 5 - корпус волновода. Сечение волноводного канала $1.295 \times 0.648 \mathrm{~mm}$.

Задача настоящей работы - теоретическое обоснование и экспериментальное подтверждение возможности создания в диапазоне частот $140-210 \mathrm{GHz}$ согласованной нагрузки, состоящей из нанометрового металлического слоя с определенными значениями толщины и электропроводности и чередующихся диэлектрических слоев.

Согласованные нагрузки на основе фотонных кристаллов представляют собой отрезки прямоугольного волновода, полностью заполненные слоистыми структурами. Структуры состоят из чередующихся слоев диэлектриков с различными значениями толщины и диэлектрической проницаемости и нанометровых слоев металла с различными значениями толщины и удельной электропроводности.

Расчет коэффициента отражения электромагнитной волны при ее нормальном падении на слоистую металлодиэлектрическую структуру проводится с использованием матрицы передачи волны для $N$-слойной структуры, аналогично тому как это было сделано в $[9,14,15]$.

Как следует из результатов расчета, выполненных на основе описанной в [9] модели, возможно создание согласованной нагрузки (рис. 1), обеспечивающей в диапазоне частот $140-210 \mathrm{GHz}$ величину

5 Письма в ЖТФ, 2018, том 44, вып. 5 

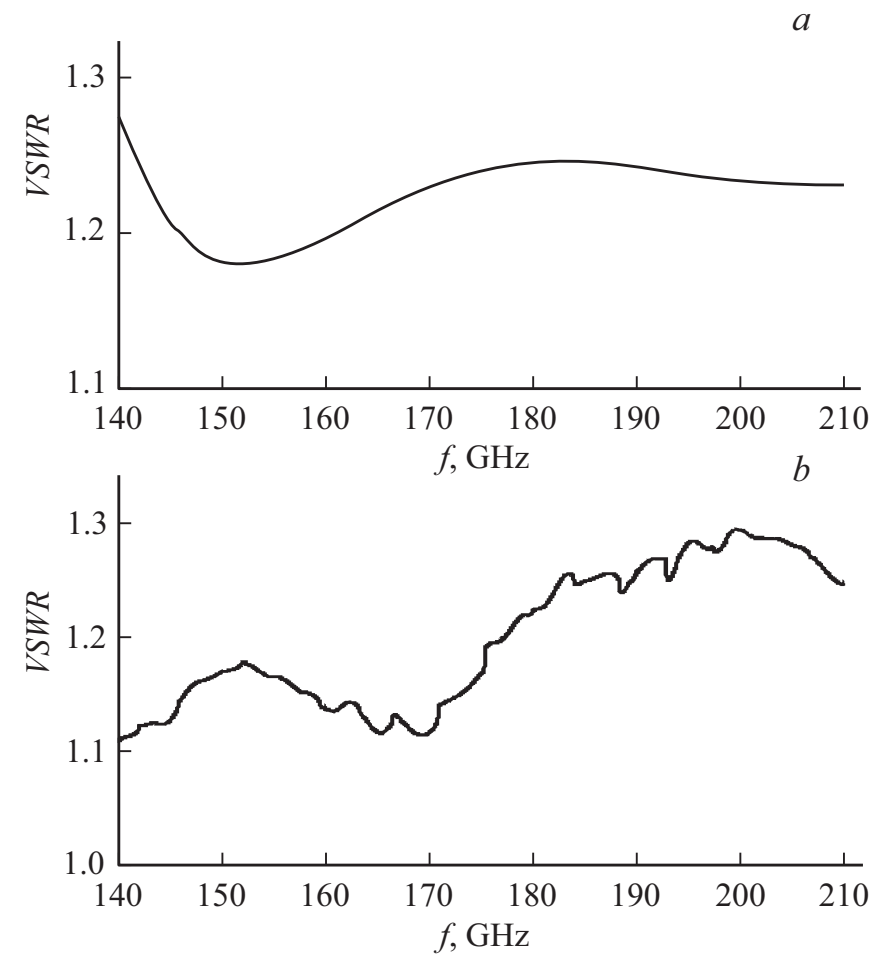

Рис. 2. Расчетная $(a)$ и экспериментальная $(b)$ частотные зависимости $V S W R$ в диапазоне $140-210 \mathrm{GHz}$.

$V S W R<1.3$ (рис. $2, a$ ) при линейных размерах нагрузки менее $0.9 \mathrm{~mm}$. Необходимо отметить, что для создания диэлектрических слоев использовались широко применяемые на СВЧ диэлектрические материалы, такие как тефлон и поликор (керамика $\mathrm{Al}_{2} \mathrm{O}_{3}$ ), обладающие малым значением тангенса угла диэлектрических потерь.

Результаты расчета приведены на рис. 2, $a$. При расчете полагалось, что диэлектрические слои 1,2 и 4 полностью заполняли волновод по поперечному сечению, их толщины составляли 340,150 и $340 \mu \mathrm{m}$.

По данным численного эксперимента была изготовлена широкополосная волноводная согласованная нагрузка, в которой диэлектрические слои представляли собой, как это было выбрано при расчете,

Письма в ЖТФ, 2018, том 44, вып. 5 
слои керамики $\left(\mathrm{Al}_{2} \mathrm{O}_{3}\right.$ с диэлектрической проницаемостью $\varepsilon_{2}=9.6$ и толщиной $150 \mu \mathrm{m}$ ) и тефлона (с диэлектрической проницаемостью $\varepsilon_{2}=2.0$ и толщиной $\left.340 \mu \mathrm{m}\right)$. Нанометровые металлические слои $(\mathrm{Cr})$ напылялись на керамическую подложку $\mathrm{Al}_{2} \mathrm{O}_{3}$ толщиной $150 \mu \mathrm{m}$. Поверхностное сопротивление $\rho$ нанометрового металлического слоя составляло $75 \Omega / \square$.

Измерения частотных зависимостей VSWR (рис. 2, $b$ ) созданной согласованной нагрузки, предназначенной для использования в диапазоне частот 140-210 GHz, проводились с помощью векторного анализатора цепей Agilent PNA N5242A и блоков расширения VDI WR 5.1.

Как следует из результатов эксперимента, созданная четырехслойная согласованная нагрузка, предназначенная для использования в диапазоне частот $140-210 \mathrm{GHz}$, имеет $V S W R<1.3$ при линейных размерах нагрузок менее $0.9 \mathrm{~mm}$. Для дальнейшего уменьшения $V S W R$ возможна дополнительная оптимизация структуры по $\varepsilon$, толщинам и числу слоев.

Отметим, что выпускаемые отечественными производителями согласованные нагрузки в диапазоне частот от 118.1 до $178.4 \mathrm{GHz}$ [16], наиболее близком к исследуемому в настоящей работе диапазону, обладая лучшими значениями $V S W R<1.1$, имеют продольные размеры, более чем в 10 раз превосходящие размеры предложенной согласованной нагрузки. Согласованные нагрузки, выполненные с использованием клинообразного поглотителя, как отмечает производитель, могут выйти из строя вследствие механического повреждения поглощающего клина [16], например при воздействии ударных нагрузок. Их меньшая по сравнению с предложенными нагрузками ударная и виброустойчивость объясняется значительной площадью поверхности, не имеющей жестко фиксированной основы. Кроме того, предложенные нагрузки отличаются от известных возможностью применения хорошо разработанных технологий изготовления входящих в их состав элементов.

Таким образом, показана теоретически и подтверждена экспериментально возможность создания в диапазоне частот $140-210 \mathrm{GHz}$ малогабаритной широкополосной согласованной нагрузки, состоящей из нанометрового металлического слоя с определенными значениями толщины и электропроводности и чередующихся сплошных диэлектрических слоев.

Работа выполнена при финансовой поддержке Министерства образования и науки РФ (государственное задание № 8.7628.2017/БЧ) и стипендии Президента РФ (СП-2622.2015.3).

5* Письма в ЖТФ, 2018, том 44, вып. 5 


\section{Список литературы}

[1] Xelszajn J. Passive and active microwave circuits. N.Y.-Chichester-BrisbaneToronto: John Wiley \& Sons, 1978. $284 \mathrm{p}$.

[2] Lee K.A., Guo Y., Stimson Ph.A., Potter K.A., Chiao J.-C., Rutledge D.B. // IEEE Transact. Antennas Propagation. 1991. V. 39. N 3. P. 425-428.

[3] Joannopoulos I.D., Villenneuve Pierre R., Fan S. // Nature. 1997. V. 386. N 13. P. 143-149.

[4] Yablonovitch E., Gmitter T.J., Leung K.M. // Phys. Rev. Lett. 1991. V. 67. N 17. P. 2295-2298.

[5] Usanov D.A., Skripal A.V., Abramov A.V., Bogolubov A.S., Skvortsov V.S., Merdanov M.K. // Proc. of the 38th Eur. Microwave Conf. Amsterdam, Netherlands, 2008. P. 484-487.

[6] Усанов Д.А., Скрипаль А.В., Абрамов А.В., Боголюбов А.С., Скворцов В.С., Мерданов М.К. // Изв. вузов. Радиоэлектроника. 2009. № 1. С. 73-80.

[7] Усанов Д.А., Скрипаль А.В., Абрамов А.В., Боголюбов А.С., Сквориов В.С., Мерданов М.К. Патент РФ на изобретение 2360336 С1 МПК Н01Р 7/00. Широкополосная волноводная согласованная нагрузка. Опубл. 27.06.2009. Бюл. № 18.

[8] Усанов Д.А., Скрипаль А.В., Мещанов В.П., Попова Н.Ф., Пономарев Д.В. Патент РФ на изобретение 2601612 С1 МПК Н01Р 1/26. Волноводная согласованная нагрузка. Заявка: 2015120704/28 2012137649/07 от 01.06.2015. Опубл. 10.11.2016. Бюл. № 31.

[9] Усанов Д.А., Мещанов В.П., Скрипаль А.В., Попова Н.Ф., Пономарев Д.В., Мерданов М.К. // ЖТФ. 2017. Т. 87. В. 2. С. 216-220.

[10] Братман В.Л., Литвак А.Г., Суворов Е.В. // УФН. 2011. Т. 181. № 8. С. 867874.

[11] Zhu Z., Zhang X., Gu J., Singh R., Tian Z., Han J., Zhang W. // IEEE Transact. Terahertz Sci. Technol. 2013. V. 3. N 6. P. 832-837.

[12] Nagatsuma T., Ducournau G., Renaud C.C. // Nature Photon. 2016. V. 10. P. 371-379.

[13] Андреев В.Г., Ангелуи А.А., Вдовин В.А., Лукичев В.Ф. // Письма в ЖТФ. 2015. T. 41. B. 4. C. 52-60.

[14] Усанов Д.А., Скрипаль А.В., Абрамов А.В., Боголюбов А.С. // ЖТФ. 2006. T. 76. B. 5. C. $112-117$.

[15] Усанов Д.А., Скрипаль А.В., Мерданов М.К., Горлицкий В.О. // ЖТФ. 2016. T. 86. B. 2. C. $65-70$.

[16] http://npp-elmika.ru/info/index.php?id=151 